\title{
UNSUSPECTED LUNG PATHOLOGY IN AUTOPSIES OF CHILDREN WITH CANCER
}

\author{
María Elena Y. Furuya ${ }^{1 *}$, Alicia Rodríguez-Velasco ${ }^{2}$, María del Carmen Rodríguez-Zepeda $^{3}$, \\ EnRiQue López-Aguilar ${ }^{4}$, Mario H. VARgas ${ }^{1}$, Martha SCIANdra-Rico ${ }^{5}$, Rocío CáRdenas-Navarrete ${ }^{6}$, \\ Olivia Madrigal-Muñiz ${ }^{7}$, Carina Feria-Kaiser ${ }^{7}$, Elba E. Delgado-González ${ }^{8 \dagger}$ \\ and Miguel ÁNGel VilLasís-KeEVer ${ }^{9}$
}

\begin{abstract}
${ }^{1}$ Research Unit in Respiratory Diseases; Services of ${ }^{2}$ Pathology, ${ }^{3}$ Hematology, ${ }^{4}$ Oncology, ${ }^{5}$ Pre-School and ${ }^{6}$ School Children, and ${ }^{8}$ Infants/Toddlers; ${ }^{7}$ Neonatal Intensive Care Unit; and ${ }^{9}$ Research Unit in Clinical Epidemiology. Hospital de Pediatría, Centro Médico Nacional Siglo XXI, Instituto Mexicano del Seguro Social, Mexico City, Mexico
\end{abstract}

\begin{abstract}
Background: Although pulmonary involvement is common in patients with cancer, its frequency and nature is seldom reported in the medical literature. Objective: To determine the frequency and type of lung pathological conditions revealed by autopsy in children with cancer. Methods: All reports from autopsies performed in children with cancer from 1989 to 2012 in a pediatric hospital were reviewed. Results: In the analyzed period, 118 autopsies ( $10.2 \%$ of all autopsies) corresponded to children who died with cancer; 76 had complete information and were included in the analysis. Children were seen in the Hematology (41 cases) or the Oncology (35 cases) services. Their median age at decease was 7 years (range, 15 days to 16.1 years) and $46.1 \%$ were females. Main diagnoses were acute lymphoblastic (31 patients) or myeloblastic (10 patients) leukemias and tumors of the central nervous system (12 patients). A pathological respiratory condition was diagnosed antemortem in 31 (40.8\%) patients, and at autopsy in $62(81.6 \%)$ cases. Omitted diagnoses occurred in 58 (76.3\%) children, being pneumonia ( 24 cases) and pulmonary hemorrhage (23 cases) the most frequent omissions. Nine patients had clinically unsuspected tumor infiltration or metastases. Conclusions: In these children with cancer, more than $80 \%$ of autopsies revealed some lung pathology, mainly of infectious or hemorrhagic nature. Thus, pulmonary involvement should be investigated in all children with cancer in a timely and intentional manner. (REV INVES CLIN. 2017;69:28-32)
\end{abstract}

Key words: Cancer. Lung pathology. Autopsy. Necropsy.

Corresponding author:

*María Elena Y. Furuya

Unidad de Investigación Médica en Enfermedades

Respiratorias

Hospital de Pediatría

Centro Médico Nacional Siglo XXI, IMSS

Av. Cuauhtémoc, 330

C.P. 06720, Ciudad de México, México

E-mail:meyfuruya@yahoo.com.mx

Received for publication: 10-11-2016

Accepted for publication: 09-01-2017 


\section{INTRODUCTION}

In the last decades, a declining trend in the rate of autopsies performed has been observed worldwide. However, there is ample evidence that the autopsy is a relevant source of diagnostic information and a learning tool for future cases. In addition, autopsies allow the evaluation of diagnostic accuracy (and therefore, assessment of the quality of hospital services), help to identify differential diagnoses, unveil unsuspected conditions, and evaluate the impact of therapeutic measures ${ }^{1-8}$. Cancer is one of the diseases in which the autopsy yields more benefits, either for research or for the improvement of medical care ${ }^{9-12}$. A number of published studies have reported autopsy findings in children with cancer, but the majority of them are focused primarily on clinical-pathological inconsistencies, causes of death, omitted diagnoses, unexpected findings, or infectious complications ${ }^{13-15}$. Although the lung is one of the most frequently affected structures in patients with cancer, the medical literature concerning pulmonary involvement in pediatric patients with cancer is scarce $^{10,12,16}$. Thus, the objective of the present study was to investigate the frequency and type of lung pathology revealed by autopsies in children with cancer.

\section{PATIENTS AND METHODS}

This was a retrolective study performed in a tertiarylevel pediatric hospital. Reports of autopsies performed from January 1989 to December 2012 in children under 17 years of age, and with a diagnosis of cancer were analyzed. Due to the large time-period analyzed, complete clinical charts could not be obtained in all patients, and thus relevant data was also obtained from death notes, death certificates, and autopsy reports. From these sources of information, each case was jointly evaluated by the medical team that was responsible for the patient and the Mortality Committee (integrated by nine specialists in pediatrics, hematology, oncology, critical care medicine, pulmonary medicine, and pathology). From these evaluations, we elaborated an adhoc database. The analyzed variables were demographic data, type of cancer, all clinical diagnoses established by clinicians including suspected pulmonary involvement, histopathological findings regarding lung pathology at autopsy, and omission of diagnoses of respiratory diseases and whether they were potentially treatable. Data were analyzed with descriptive statistics.

\section{RESULTS}

During the study period, 1162 autopsies were performed in the hospital, with 118 (10.2\%) corresponding to patients with cancer. Complete data could be obtained from 76 cases and they were included in the present analysis. Forty-one patients (53.9\%) were seen in the Hematology service, where they were diagnosed with acute lymphoblastic leukemia (31 patients) or acute myeloid leukemia (10 patients). The remaining 35 patients ( $46.1 \%$ ), were seen by the Oncology service, being tumors of the central nervous system the most frequent diagnosis (Table 1 ). The median age of the population was 7 years (range, 15 days to 16.1 years), and $46.1 \%$ were females. In patients with hematological disorders, the main diagnosis at autopsy always derived from the clinical diagnosis; thus, in these patients the agreement between both diagnoses was $100 \%$. In turn, in patients with nonhematological cancer, the clinical-autopsy concordance of the main diagnosis was $88.6 \%$, since the diagnosis at autopsy was different in 4 out of 35 patients. These 4 discordant cases had clinical diagnoses of neuroblastoma, subependimal astrocytoma, meningeal tuberculosis, and primitive neuroectodermal tumor. However, the autopsies revealed that in fact they corresponded to non-Hodgkin lymphoma with dissemination to lumbar spinal canal and brain; right frontal primitive neuroectodermal tumor extended to the right lateral ventricle, nucleus caudalis, corpus callosum and left frontal lobe; central nervous system primary lymphoblastic lymphoma with leptomeningeal infiltration; and a well-differentiated neuroblastoma, respectively.

Regarding the cause of death, in 5 patients with septic or mixed shock, the anatomopathological cause of death could not be determined by autopsy. In the remaining 71 patients, the clinical-autopsy concordance on the cause of death was $69 \%$.

\section{Respiratory findings at autopsy}

At the time of death, $31(40.8 \%)$ patients had one or more clinical diagnoses of lung involvement mentioned in any of the documents we used to obtain the information, contrasting with the total number of 62 (81.6\%) patients with some lung pathology discovered during the autopsy. The main respiratory findings at autopsy are shown in table 2 . 
Table 1. Anatomopathological diagnosis of the pediatric oncology patients (35 cases)

\begin{tabular}{|c|c|c|}
\hline Topography or diagnosis & Number (\%) & Diagnosis (Number) \\
\hline Central nervous system & $12(34.2)$ & $\begin{array}{l}\text { Anaplastic astrocytoma, brain stem (2) } \\
\text { Glioblastoma (2) } \\
\text { Anaplastic ependymoma (1) } \\
\text { Myxopapillary ependymoma (1) } \\
\text { Gangliocytoma (1) } \\
\text { Germinoma (1) } \\
\text { Pineal anlage tumor (1) } \\
\text { Primitive neuroectodermal tumor (1) } \\
\text { Atypical teratoid/rhabdoid tumor (1) } \\
\text { Lymphoblastic lymphoma (1) }\end{array}$ \\
\hline Lymphoma & $7(20)$ & $\begin{array}{l}\text { Hodgkin (2) } \\
\text { Lymphoblastic lymphoma ( } 1 \text { ) } \\
\text { Hemophagocytic syndrome (1) } \\
\text { Large cells ( } 2 \text { ) } \\
\text { Angiocentric (1) }\end{array}$ \\
\hline Adrenal gland & $2(5.71)$ & Neuroblastoma \\
\hline Sympathetic chain & $2(5.71)$ & Neuroblastoma \\
\hline Soft tissue & $4(11.42)$ & $\begin{array}{l}\text { Parameningeal rhabdomyosarcoma (1) } \\
\text { Mediastinal primitive neuroectodermal tumor (1) } \\
\text { Mediastinal malignant Schwannoma (1) } \\
\text { Retroperitoneal malignant masenchymoma (1) }\end{array}$ \\
\hline Bone & $3(8.57)$ & Osteosarcoma \\
\hline Liver & $2(5.71)$ & Hepatoblastoma \\
\hline Kidney & $2(5.71)$ & Nephroblastoma \\
\hline Biliary ducts & $1(2.8)$ & Rhabdomyosarcoma \\
\hline
\end{tabular}

Table 2. Respiratory diagnoses made at autopsy in 76 children who died with cancer

\begin{tabular}{lcll}
\hline Pneumonia & $30(39.5)$ & Metastases & $3(3.9)$ \\
Pulmonary hemorrhage & $30(39.5)$ & Diffuse alveolar damage & $3(3.9)$ \\
Tracheobronchitis & $13(17.1)$ & Atelectasis & $3(3.9)$ \\
Pulmonary edema & $9(11.8)$ & Pulmonary thromboembolism & $2(2.6)$ \\
Tumor infiltration & $6(7.9)$ & Pulmonary infarction & $2(2.6)$ \\
Pleural effusion & $5(6.6)$ & Other & $6(7.9)$ \\
Hemothorax & $3(3.9)$ & & \\
\hline
\end{tabular}

Data correspond to number (percentage) of patients with the diagnosis.

Omitted diagnoses (i.e., pathological abnormalities discovered at autopsy but not mentioned in the clinical chart, death note or death certificate) occurred in $58(76.3 \%)$ children, being pneumonia ( 24 cases) and/or pulmonary hemorrhage ( 23 cases) the most frequent diagnoses found in $40(52.6 \%)$ patients. From the 76 patients included in the study, it was possible to analyze 70 to decide whether or not their pulmonary involvement was potentially treatable. In 35 (50\%) patients, the attending medical team and the Mortality Committee decided that the complication was treatable.
It is worthy to note that the autopsy detected tumor infiltration in 6 patients and metastases in other 3 patients, all of them clinically unsuspected. These complications occurred in 5 children with leukemia, 2 children with Hodgkin's lymphoma, and 2 children with osteosarcoma. In addition, from the 6 children with tumor infiltration, 2 also had pulmonary hemorrhage, 2 had pneumonia (potentially treatable), and 1 had both processes.

At the time of their last hospital admission, there were 3 patients in terminal stage and 1 in premortem 
condition. Only in one of them the pulmonary complication (herpes virus pneumonia) was considered treatable.

\section{DISCUSSION}

Technological advances in diagnostic procedures have not diminished the value of the autopsy. In 2010, Scordi-Bello et al. ${ }^{17}$ found similar rates of clinical-pathological discrepancy in three clinical settings that differed in the amount of antemortem diagnostic workup, thus refuting the hypothesis that the availability of diagnostic procedures decreases the frequency of discrepancies in the diagnosis. A systematic review by Shojania et al. ${ }^{2}$ concluded that the capacity of the autopsy to identify diagnoses unsuspected before death is high enough as to reinforce the recommendation of performing autopsies.

The autopsy continues to be well recognized as a source of relevant medical information (accuracy of diagnoses, discovery of unexpected findings, feedback regarding therapeutic outcome, etc), a tool for learning, and a measure of quality control. In public health, it is an indicator of the behavior of health systems through time, and allows comparisons between them ${ }^{1,3-6,11,15,17-21}$. In spite of this, specifically in pediatric patients with oncological diseases, the usefulness of the autopsy has been questioned because the main diagnosis, i.e., the malignant disease, was fully corroborated (for example, by biopsy) when the patient was still alive. This belief explains the low percentage of autopsies performed in children with hemato-oncological diseases, as has been noted in case-series reports. For example, Buckner et al. ${ }^{15}$ analyzed 533 autopsies performed in a 20-year period, and they found that only 43 cases $(8.06 \%$ ) had a main diagnosis of neoplasia, with $25.6 \%$ of misdiagnoses and $23.3 \%$ of omitted diagnoses. These authors concluded that the autopsy continues to provide previously unknown diagnostic information and remains a valuable tool for pediatricians and pediatric oncologists. This last conclusion has been confirmed in a number of studies showing that main diseases have a clinical-pathological discordance between $15 \%$ and $53 \%$ 2,4,6,9,13-17.

The autopsy can provide unexpected information even in children dying due to end-stage cancer, and hence the procedure is still advisable ${ }^{15}$. Moreover, the complexity of the disease may lead to a delay or omission of some diagnoses, mainly during exacerbations or at the end-stage of the disease ${ }^{10}$. In spite of this evidence, little emphasis has been made on respiratory comorbidities, which are among the most frequent clinical causes of death in these patients.

Acute or chronic pulmonary complications in patients with current or past cancer are well characterized in the medical literature, both in children and adults ${ }^{12,22-26}$. These complications are diverse and include infections, fibrosis, diffuse alveolar hemorrhage; tumor infiltration, metastases, atelectasis and vascular or hemorrhagic conditions such as vascular leakage with edema and infarction, hemorrhage, pulmonary thromboembolism, etc. ${ }^{10,12,16,22,27}$. In contrast, their participation and magnitude in the autopsy of patients with cancer are scant and unspecific ${ }^{10,11,13,16}$.

In the present study, pulmonary involvement was very frequent, since more than half of the patients presented pneumonia and/or pulmonary hemorrhage, which can be explained by the immunosupression and the hematological abnormalities due to the disease and treatment ${ }^{27}$. All the pulmonary manifestations mentioned in the medical literature were found in our population, such as vascular-hemorrhagic pathologies (pulmonary edema, thromboembolism or infarction) and tumoral activity (infiltration and metastases). Lung infection and bleeding were the two most conditions most frequently overdiagnosed, but most importantly, these were also the two most frequently omitted diagnoses in up to $52.6 \%$ of the cases. Some patients had both conditions, but 17 cases only had pneumonia, which could be potentially treatable, thereby increasing the chances of the patient's survival.

Another relevant finding in this series was tracheobronchitis associated with mechanical ventilation. This condition is considered as a precursor of ventilatorassociated pneumonia and its presence is an indication for antibiotic and antiinflammatory therapy, which could prevent its evolvement into a pneumonic process and avoid a fatal outcome ${ }^{28}$. Tracheobronchitis is usually an endoscopic finding during bronchoscopy in patients in critical condition. The clinical and laboratory data suggestive of this condition are fever, sputum production, leukocytosis or leukopenia, and the absence of a new or progressive radiographic lung pattern. These signs must alert the clinicians in order to initiate a timely and specific treatment, preferentially based on microbiological 
results from sputum or bronchoalveolar lavage samples, in an attempt to avoid progression of the disease to distal airways.

A potential limitation of this retrolective study was that a relatively large number of patients who died with cancer (42 out of 118 ) could not be included in the study. The main reason for this loss was that the sources of information (clinical records, death note, death certificate, and autopsy report) did not contain enough relevant data on key variables of the study. However, even with this drawback, we consider that the number of children included in our study was high and the analysis yielded important information about pulmonary involvement in patients with cancer. In this context, our results revealed that a high percentage of lung pathologies occurred in patients with neoplastic diseases, mainly pneumonia and/or pulmonary hemorrhage, and that they frequently contributed to the patient's worsening and death. This finding should alert clinicians to begin preventive measures, have a high degree of suspicion of tracheobronchitis in patients under mechanical ventilation, and intentionally include the search for respiratory infection or hemorrhage into the workup of worsening episodes in these patients. Further studies are needed to corroborate our results.

\section{CONFLICT OF INTEREST}

All authors were members of the former Mortality Committee, chaired by Dr. María Elena Y. Furuya.

\section{REFERENCES}

1. Zarbo RJ, Baker PB, Howanitz PJ. The autopsy as a performance measurement tool-diagnostic discrepancies and unresolved clinical questions: a College of American Pathologists Q-Probes study of 2479 autopsies from 248 institutions. Arch Pathol Lab Med. 1999;123:191-8.

2. Shojania KG, Burton EC, McDonald KM, Goldman L. Changes in rates of autopsy-detected diagnostic errors over time: a systematic review. JAMA. 2003;289:2849-56.

3. Newton D, Coffin CM, Clark EB, Lowichik A. How the pediatric autopsy yields valuable information in a vertically integrated health care system. Arch Pathol Lab Med. 2004;128:1239-46.

4. Roulson J, Benbow EW, Hasleton PS. Discrepancies between clinical and autopsy diagnosis and the value of post mortem histology; a meta-analysis and review. Histopathology. 2005;47:551-9.
5. Burton JL, Underwood J. Clinical, educational, and epidemiological value of autopsy. Lancet. 2007;369:1471-80.

6. Feinstein JA, Ernst LM, Ganesh J, Feudtner C. What new information pediatric autopsies can provide: a retrospective evaluation of 100 consecutive autopsies using family-centered criteria. Arch Pediatr Adolesc Med. 2007;161:1190-6.

7. Garcia Soler P, Martinez-Ferriz MC, Martin Carballido S, Milano Manso G. [Current situation and usefulness of autopsy in a pediatric intensive care unit]. An Pediatr (Barc). 2013;78:81-7.

8. Alonso Villan E, Perez Rodriguez J, Rodriguez Jl, et al. [Infant mortality in a third level pediatric hospital. therapeutic effort limitation, clinical-pathological agreement and diagnostic accuracy]. An Pediatr (Barc). 2012;76:343-9.

9. Burton EC, Troxclair DA, Newman WP. Autopsy diagnoses of malignant neoplasms: how often are clinical diagnoses incorrect? JAMA. 1998;280:1245-8

10. Doran HM, Sheppard MN, Collins PW, Jones L, Newland AC, van der Walt JD. Pathology of the lung in leukaemia and lymphoma: a study of 87 autopsies. Histopathology. 1991;18:211-9.

11. Hill RB, Anderson RE. The autopsy in oncology. CA Cancer J Clin. 1992:42:47-56.

12. Stover DE, Kaner RJ. Pulmonary complications in cancer patients. CA Cancer J Clin. 1996;46:303-20.

13. Sirkia K, Saarinen-Pihkala UM, Hovi L, Sariola H. Autopsy in children with cancer who die while in terminal care. Med Pediatr Oncol. 1998;30:284-9.

14. Hamre MR, Williams J, Chuba P, Bhambhani K, Ravindranath $Y$, Severson RK. Early deaths in childhood cancer. Med Pediatr Oncol. 2000;34:343-7

15. Buckner T, Blatt J, Smith SV. The autopsy in pediatrics and pediatric oncology: a single-institution experience. Pediatr Dev Pathol. 2006;9:374-80.

16. Terrabuio Junior AA, Parra ER, Farhat C, Capelozzi VL. Autopsyproven causes of death in lungs of patients immunocompromised by secondary interstitial pneumonia. Clinics (Sao Paulo). 2007;62:69-76.

17. Scordi-Bello IA, Kalb TH, Lento PA. Clinical setting and extent of premortem evaluation do not predict autopsy discrepancy rates. Mod Pathol. 2010;23:1225-30.

18. Fruhbeck G. Death of the teaching autopsy: advances in technology have not reduced the value of the autopsy. BMJ. 2004;328: 165-6; [Discussion 7].

19. Jennings CR, Bradley PJ. Are autopsies useful? Do premorbid findings predict postmortem results in head and neck cancer patients? Ann R Coll Surg Engl. 2002;84:133-6.

20. Peres LC. Review of pediatric autopsies performed at a university hospital in Ribeirao Preto, Brazil. Arch Pathol Lab Med. 2006; 130:62-8.

21. van den Tweel JG. Autopsy pathology should become a recognised subspecialty. Virchows Arch. 2008;452:585-7.

22. Jenney ME. Malignant disease and the lung. Paediatr Respir Rev. 2000;1:279-86

23. Brodoefel H, Faul C, Salih H, Vogel W, Fenchel M, Horger M. Therapy-related noninfectious complications in patients with hematologic malignancies: high-resolution computed tomography findings. J Thorac Imaging. 2013;28:W5-11.

24. Poletti V, Trisolini R, Tura S. Pulmonary disease in patients with hematologic malignancies. Sarcoidosis Vasc Diffuse Lung Dis. 2002;19:29-45.

25. Huang TT, Hudson MM, Stokes DC, Krasin MJ, Spunt SL, Ness KK. Pulmonary outcomes in survivors of childhood cancer: a systematic review. Chest. 2011;140:881-901.

26. Josephson MB, Goldfarb SB. Pulmonary complications of childhood cancers. Expert Rev Respir Med. 2014;8:561-71.

27. Furuya ME, Gonzalez-Martinez F, Vargas MH, Miranda-Novales MG, Bernaldez-Rios R, Zuniga-Vazquez G. Guidelines for diagnosing and treating pulmonary infiltrates in children with acute leukaemia: impact of timely decisions. Acta Paediatr. 2008;97: 928-34.

28. Craven DE, Chroneou A, Zias N, Hjalmarson KI. Ventilator-associated tracheobronchitis: the impact of targeted antibiotic therapy on patient outcomes. Chest. 2009;135:521-8. 